\title{
Effects of tumour acidification with glucose + MIBG on the spontaneous metastatic potential of two murine cell lines
}

\author{
T Kalliomäki ${ }^{1,2}$ and RP Hill, ${ }^{*, 2,3}$
}

'Experimental Therapeutics Division, Ontario Cancer Institute/Princess Margaret Hospital, Toronto, Ontario, Canada M5G 2M9; ${ }^{2}$ Department of Medical Biophysics; ${ }^{3}$ Department of Radiation Oncology, University of Toronto, 610 University Avenue, Toronto, Ontario, Canada M5G 2M9

\begin{abstract}
In addition to hypoxia, acidic extracellular $\mathrm{pH}\left(\mathrm{pH}_{\mathrm{e}}\right)$ is recognised as one of the microenvironmental characteristics of solid tumours. A number of studies have examined ways to increase tumour acidity in order to improve tumour-specific targeting of certain drugs and the effectiveness of hyperthermia. However, previous data have shown that exposure of murine tumour cells to acid conditions in culture can enhance their metastatic potential when injected subsequently into mice, raising the concern that deliberate tumour acidification might increase the probability of metastasis. In this study, we examined the effects of in vivo tumour acidification and hypoxia on the spontaneous metastatic potential of the murine $\mathrm{KHT}-\mathrm{C}$ fibrosarcoma and $\mathrm{BI} 6 \mathrm{FI}$ melanoma cell lines. A tumourspecific increase in extracellular acidity, demonstrated by measurements with $\mathrm{pH}$ electrodes, was achieved by daily intraperitoneal injections of meta-iodo-benzylguanidine (MIBG) and/or glucose. This method of tumour acidification during tumour growth did not significantly enhance the spontaneous metastatic potential of the two murine cell lines.
\end{abstract}

British Journal of Cancer (2004) 90, 1842- 1849. doi: 10. I038/sj.bjc.660I766 www.bjcancer.com

Published online 13 April 2004

(C) 2004 Cancer Research UK

Keywords: acidic pH; MIBG; hypoxia; metastasis; murine tumours

Tumour acidity is probably caused by excessive production of lactic and carbonic acids and their insufficient clearance by abnormal tumour vasculature (Newell et al, 1993; Stubbs et al, 2000; Griffiths et al, 2001). Several studies have examined ways to further reduce extracellular $\mathrm{pH}\left(\mathrm{pH}_{\mathrm{e}}\right)$ in order to improve the therapeutic index of $\mathrm{pH}$ responsive cancer therapies (Wike-Hooley et al, 1984; Thistlethwaite et al, 1987; Tannock and Rotin, 1989; Jahde et al, 1992; Kuin et al, 1994). Acidification of the tumour extracellular space with glucose alone or in combination with meta-iodo-benzylguanidine (MIBG) provides a means for preferential intracellular accumulation and enhanced cytotoxicity of weakly acidic chemotherapeutic drugs, such as chlorambucil (Kuin et al, 1999; Kozin et al, 2001) and increases tumour cell sensitivity to hyperthermia (Ohtsubo et al, 2001). Acidification of human colonic xenografts has also been shown to enhance their sensitivity to aminolevulinic acid-mediated photodynamic therapy (Piot $e t$ al, 2001).

Acidic $\mathrm{pH}$ has also been implicated in progression of cultured human melanoma cells, which were found to have increased invasiveness through Matrigel following acidic culture conditions (Martinez-Zaguilan et al, 1996). A similar observation was made for metastatic B16 mouse melanoma cells where an increase in invasiveness was accredited to an acidosis-induced increase in expression of a gelatinase thought to be gelatinase B (matrix metalloproteinase 9). The relative gelatinase activity was further

* Correspondence: RP Hill, Experimental Therapeutics Division, Ontario Cancer Institute/Princess Margaret Hospital, 610 University Avenue, Toronto, Ontario, Canada M5G 2M9; E-mail: hill@uhnres.utoronto.ca Received 23 May 2003; revised I I February 2004; accepted II February 2004; published online 13 April 2004 shown to be in good agreement with the different metastatic potentials of three different B16 subclones (Kato et al, 1992). In separate studies, the ability of murine B16F1 melanoma and KHT fibrosarcoma cells to form lung metastases after intravenous injection was shown to increase significantly after exposure to acidic conditions in culture (Schlappack et al, 1991; Jang and Hill, 1997). In humans, elevated tumour lactate concentrations, which generally correlate with reduced $\mathrm{pH}_{\mathrm{e}}$, have been found to predict the likelihood of metastatic disease in head and neck and cervical carcinomas (Parkins et al, 1997; Walenta et al, 2000; Brizel et al, 2001). In addition to upregulated expression of invasion-enhancing proteins such as gelatinases, this increase in metastases may be related to acidosis-induced elevation of interleukin-8 (IL-8) and/or vascular endothelial growth factor (VEGF), factors known for their angiogenic potential (Shi et al, 1999; Xu and Fidler, 2000; Fukumura et al, 2001; Shi et al, 2001).

High lactate concentrations and low $\mathrm{pO}_{2}$ levels in tumours have been shown to correlate with increased likelihood of metastatic disease (Walenta et al, 2000; Brizel et al, 2001; Cairns et al, 2001; Hill et al, 2001). However, low $\mathrm{pO}_{2}$ levels and acidic $\mathrm{pH}_{\mathrm{e}}$ are also known to coexist in solid tumours and thus it has been difficult to separate the effects of these two factors on metastatic potential in vivo (Helmlinger et al, 1997; Rofstad, 2000; Hill et al, 2001). To clarify further the relationship between acidic $\mathrm{pH}$ and metastatic tumour progression, we injected MIBG in combination with glucose into tumour-bearing mice; this treatment results in selective tumour acidification by inhibiting mitochondrial respiration at complex I of the electron transport chain and by stimulation of lactic acid production through anaerobic glycolysis (Loesberg et al, 1990; Jahde et al, 1992; Kuin et al, 1994, 1999). We examined the relative contribution of oxygenation and acidity to the spontaneous metastatic potential of the murine KHT-C 
fibrosarcoma and $\mathrm{B} 16 \mathrm{~F} 1$ melanoma cells by treating tumourbearing mice daily with glucose + MIBG alone or in combination with a strategy to simulate acute hypoxia (Cairns et al, 2001).

\section{MATERIALS AND METHODS}

\section{Animals and tumours}

The experiments were carried out with two previously described murine cell lines: KHT-C fibrosarcoma and B16F1 melanoma, which were maintained using an alternating in vivo-in vitro growth protocol (Bristow et al, 1990). Cells were propagated in vitro in $\alpha$-MEM media supplemented with $10 \%$ foetal calf serum and antibiotics. For in vivo experiments $2-5 \times 10^{5}$ cells were injected intramuscularly into the gastrocnemius muscle of the left hind leg of 8-12-week old C3H-HeJ male (KHT-C) and C57Bl/CRL female (B16F1) mice to produce tumours as described previously (Cairns et al, 2001). Tumour growth was monitored daily by leg diameter measurements, which were converted into tumour weight by a previously made standard curve. Animals were maintained in the Animal Resource Centre of the Ontario Cancer Institute/ Princess Margaret Hospital and all procedures on the animals had the ethical approval of the Animal Care Committee in compliance with the guidelines of the Canadian Council on Animal Care. These guidelines meet the standards required by the UKCCCR (Workman et al, 1998).

\section{$\mathrm{pH}_{\mathrm{e}}$ and $\mathrm{pO}_{2}$ measurements}

Prior to and at 1 and $3 \mathrm{~h}$ following glucose \pm MIBG injections, mice with tumours weighing $\sim 0.4-0.5 \mathrm{~g}(\sim 9.0-10.0 \mathrm{~mm})$ were restrained in a jig. Following a two-point calibration (Fisher Scientific standardising buffers 4.01 and 7.00; slope min $80 \%$ ), a $21 \mathrm{G}$ needle electrode (type MI-418, Microelectrodes Inc., Bedford, $\mathrm{NH}$, USA connected to ORION pH meter, model 230A, Boston MA, USA) was inserted into the tumour through a premade $21 \mathrm{G}$ needle puncture in the skin and withdrawn in a stepwise manner to record $\mathrm{pH}$ values at different depths. A reference electrode (type MI-402, Microelectrodes Inc., Bedford, NH, USA) was placed subcutaneously in the same leg. Any drift caused by protein contamination of the needle probe was assessed by placing both of the probes back into $\mathrm{pH} 7.00$ standardising buffer after the measurement of each tumour and by recording the difference that had occurred during the measurement. All of the $\mathrm{pH}$ values presented are corrected for their individual drifts, which on average was $+0.03 \mathrm{pH}$ units following approximately $10 \mathrm{~min}$ measurement interval. This drift increased significantly with increasing measurement time, thus preventing accurate measurements of long-term $\mathrm{pH}_{\mathrm{e}}$ changes in the tumours. The probes were rinsed with distilled water and recalibrated with $\mathrm{pH} 7.00$ buffer following measurements in every mouse.

Measurements of tissue oxygenation were made using the fibreoptic-based OxyLite system (Oxford Optronix, Oxford, UK) as described previously (Cairns et al, 2001) in a restraint set-up identical to that used for $\mathrm{pH}_{\mathrm{e}}$ measurements. The probe was placed initially in a region of the tumour with a $\mathrm{pO}_{2}$ value around 5$10 \mathrm{mmHg}$ and then left in place for a number of hours. Data recording was initiated within $30 \mathrm{~min}$ of injection with glucose + MIBG. To obviate the possibility of metastatic contribution by dislodged tumour cells, no needle electrode or $\mathrm{pO}_{2}$ measurements were made in the tumours of mice used to generate the spontaneous metastasis data. All measurements were carried out without general anaesthetics.

\section{Tumour treatment protocol for metastasis experiments}

Treatment to induce tumour acidification was started when the diameter of the tumour-bearing leg reached $7.5 \mathrm{~mm}(0.23 \mathrm{~g}$; about
5-7 days after tumour inoculation). Earlier initiation of treatment resulted in a significant inhibition of tumour growth. Mice in the treatment group were injected with $30 \mathrm{mg} \mathrm{kg}^{-}$MIBG (a gift from Dr Dewhirst, Durham, NC, USA) in phosphate-buffered saline (PBS) intraperitoneally (i.p.), immediately followed by $3 \mathrm{~g} \mathrm{~kg}^{-1}$ glucose (i.p.) in distilled water. Owing to different tolerance levels, the drug was administered in different schedules to the two different mouse strains. The $\mathrm{C} 3 \mathrm{H}-\mathrm{HeJ}$ males with KHT-C tumours received glucose + MIBG on every other day and on the intervening day only glucose was administered at a dose of $3 \mathrm{~g} \mathrm{~kg}^{-1}$. The $\mathrm{C} 57 \mathrm{Bl} / \mathrm{CRL}$ females with B16F1 tumours received glucose + MIBG on two consecutive days followed by a day on which only glucose was administered at a dose of $3 \mathrm{~g} \mathrm{~kg}^{-1}$. Control animals received an equal number of daily PBS injections. This treatment schedule was repeated until a predetermined tumour weight was reached. In two experiments, a separate group of KHT$\mathrm{C}$ tumour-bearing animals were treated with glucose alone, receiving single daily doses of glucose at $3 \mathrm{~g} \mathrm{~kg}^{-1}$.

In experiments identified as 'combination treatments', the above injections were given together with daily treatments to simulate acute hypoxia. This consisted of 12 alternating breathing cycles of $10 \mathrm{~min} 7 \% \mathrm{O}_{2}$, balance $\mathrm{N}_{2}$ and $10 \mathrm{~min}$ air for the treatment animals and of $240 \mathrm{~min}$ air breathing for the control animals. In the treatment animals, this resulted in $\mathrm{pO}_{2}$ fluctuations between approximately 40 and $10 \mathrm{mmHg}$ in normal muscle and between $<10$ and near $0 \mathrm{mmHg}$ in the tumour. The acute hypoxia treatment was started on the day following tumour cell inoculation as was done previously (Cairns et al, 2001). During the days when animals received the combination treatment, control mice were injected first (with PBS) followed by the treatment group (with glucose \pm MIBG). Immediately following the i.p. injections, animals were exposed to either the control or acute treatment conditions of the gassing programme.

Mice with KHT-C tumours were killed when the tumour weight reached $0.45 \pm 0.05 \mathrm{~g}(9.0 \pm 0.5 \mathrm{~mm} ; 4-5$ days of tumour-acidifying treatment). Owing to their higher drug tolerance levels and lower metastatic efficiency, mice with B16F1 tumours were killed when the tumour weight reached $1.7 \pm 0.17 \mathrm{~g}(15.0 \pm 0.5 \mathrm{~mm})$ or a maximum of 6 days of tumour-acidifying treatment, whichever end point was reached first. The lungs were then removed for histological assessment of micrometastases where four individual $5 \mu \mathrm{m}$ sections, separated by at least $200 \mu \mathrm{m}$, were obtained from each lung and examined as described previously (Cairns et al, 2001). Experiments examining metastasis with acute hypoxia alone or in combination with glucose + MIBG injections in the KHT-C model were repeated four times with 5-12 mice per repeat group with total number in each group ranging from 28 to 33. Glucose with or without acute hypoxia experiments in the KHT-C model was repeated twice with 7-13 animals per repeat group and 17-23 animals in total. A single experiment with 13-15 animals per group was carried out to examine metastasis in the B1F1 model.

\section{Tumour treatment protocol for nonmetastasis experiments}

Additional mice were used to assess the effects of previously described tumour microenvironmental manipulations on tumour $\mathrm{pH}_{\mathrm{e}}$. Generally, pretreatment measurements were obtained 1 day prior to or on the day of treatment. For measurements of tumour $\mathrm{pH}_{\mathrm{e}}$ following acute hypoxia, one mouse was removed from the treatment chamber and tumour $\mathrm{pH}_{\mathrm{e}}$ was measured during the first reoxygenation cycle of the hypoxia treatment. The next mouse was measured during the second reoxygenation cycle and this was repeated until all of the animals were measured during $\sim 160$ min of acute hypoxia. When this treatment was combined with tumouracidifying injections, mice were injected with one dose of glucose + MIBG prior to treatment with acute hypoxia and were measured as described for acute hypoxia treatment alone. Mice used to examine the kinetics of $\mathrm{pH}_{\mathrm{e}}$ reduction received multiple 
injections in a schedule similar to that used with animals in the metastasis experiment.

\section{Statistical analysis}

The Student's $t$-test with Bonferroni correction was applied to the normally distributed data sets (the $\mathrm{pH}_{\mathrm{e}}$ values). The KruskalWallis ranking test was used on the nonparametric data sets with three or more treatment groups with the limit of statistical significance set at $P<0.05$. A power analysis of the metastasis data was performed to determine its ability to detect a difference. As the data is not normally distributed, it was log-normalized and the pooled variance was calculated. Methods described by Bausell and Li (2002) were used to determine the minimum difference that could have been detected with a $P$-value of 0.05 and a power of $80 \%$.

\section{RESULTS}

\section{Effects of glucose \pm MIBG and acute hypoxia on tumour $\mathrm{pH}_{\mathrm{e}}$}

Pooled $\mathrm{pH}_{\mathrm{e}}$ values measured before and approximately $1 \mathrm{~h}$ after treatment demonstrate the degree of acidification achieved with various treatments in the KHT-C (Figure 1A) and in the B16F1 (Figure 1B) tumours. Maximal acidification of the KHT-C tumours (mean change in $\mathrm{pH}_{\mathrm{e}}: 0.24 \mathrm{U} ; \quad P=1.0 \times 10^{-8}$ ) was observed following glucose + MIBG injections. This treatment also significantly acidified the $\mathrm{B} 16 \mathrm{~F} 1$ tumours (mean change in $\mathrm{pH}_{\mathrm{e}}: 0.25 \mathrm{U}$; $P=6.6 \times 10^{-5}$ ), as did acute hypoxia (mean change in $\mathrm{pH}_{\mathrm{e}}: 0.13 \mathrm{U}$; $P=0.027$ ), but the B16 F1 tumours were found to become most acidic when these two treatment modalities were combined (mean change in $\mathrm{pH}_{\mathrm{e}}: 0.35 \mathrm{U} ; P=8.2 \times 10^{-7}$ ). In B16F1 tumours, the acute hypoxia + glucose + MIBG-treated group is significantly different from the glucose + MIBG-treated group $\left(P=3.35 \times 10^{-9}\right)$. In the KHT-C tumours, addition of acute hypoxia to glucose + MIBG injections increased mean tumour $\mathrm{pH}_{\mathrm{e}}$ as compared to the injections alone (mean difference: $0.08 \mathrm{U}$ ). Acute hypoxia alone also increased KHT-C tumour $\mathrm{pH}_{\mathrm{e}}$ (mean change in $\mathrm{pH}_{\mathrm{e}}: 0.10 \mathrm{U}$ $P=0.016$ ), but the biological significance of this increase remains undetermined. In accordance with previous reports (Jahde et al, 1992; Zhou et al, 2000), glucose + MIBG injections had no significant effect on normal tissue (untreated muscle $\mathrm{pH}_{\mathrm{e}}$ : $7.00 \pm 0.074$ vs $7.07 \pm 0.046$ s.e.m. $1 \mathrm{~h}$ postinjections).

Examples of individual tumour responses during the first 4 days of tumour-acidification treatment with glucose + MIBG are shown in Figure 2. In most tumours, measurements of mean $\mathrm{pH}_{\mathrm{e}}$ values in individual mice showed maximal acidification within $1 \mathrm{~h}$ after injections and return of these values near to their pretreatment values within $3 \mathrm{~h}$ of injection. The mean degree of KHT-C tumour acidification following glucose + MIBG injections ranged from 0.06 to $0.28 \mathrm{pH}$ units. The mean degree and duration of tumour acidification achieved with less toxic glucose on days 8 and 10 for KHT-C (Figure 2A) appears equivalent to those achieved with glucose + MIBG on days 7 and 9, which would suggest the use of glucose alone for tumour acidification to limit the observed toxicity. However, when used without intervening MIBG injections, a dose of up to $6 \mathrm{~g} \mathrm{~kg}^{-1}$ glucose resulted in only a $0.1 \mathrm{U}$ reduction in tumour $\mathrm{pH}_{\mathrm{e}}$, which returned back to normal within $1 \mathrm{~h}$ (data not shown). This moderate tumour sensitivity to glucose suggests that the greater mean degree of tumour acidification $(0.26$ $\mathrm{pH}$ units) achieved with glucose alone in Figure 2A, is likely due to inflated pretreatment measurements, which on the days following glucose + MIBG injections, are $0.19 \mathrm{pH}$ units above the mean untreated $\mathrm{pH}_{\mathrm{e}}$ levels of 7.12. This apparent overcompensation of tumour $\mathrm{pH}_{\mathrm{e}}$ in response to glucose + MIBG within $24 \mathrm{~h}$ of injections was taken into account in generating data for panel $\mathrm{B}$,
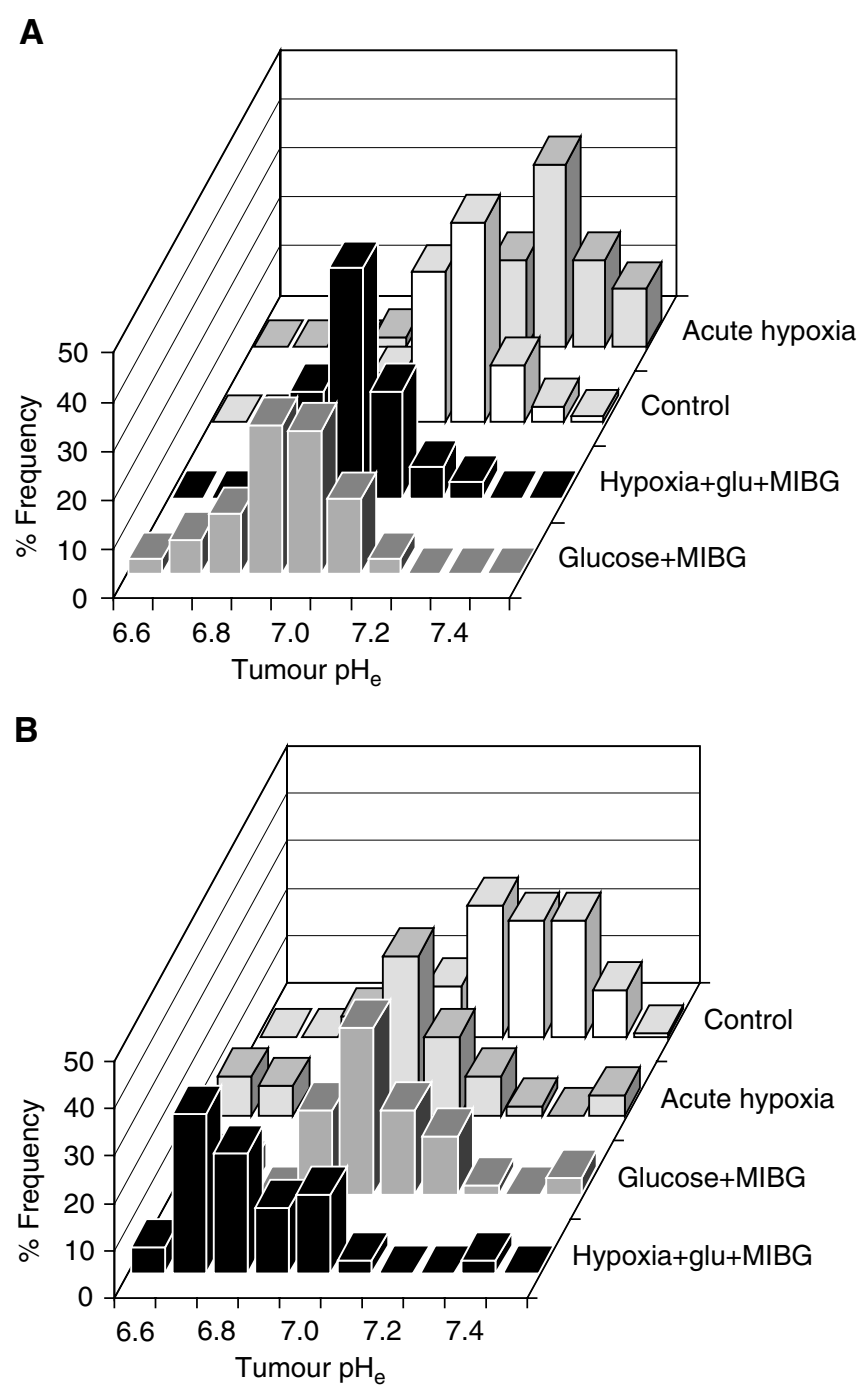

Figure I Histograms of pooled $\mathrm{pH}_{\mathrm{e}}$ values before and after treatment in KHT-C and BI6FI tumours. (A) KHT-C: Control: pretreatment measurements from animals used for post-treatment measurements, obtained I day prior to or on the day of treatment. Mean $\mathrm{pH}_{\mathrm{e}}=7.13 \pm 0.017 ; \mathrm{N}=25$ $n=179$. Glucose + MIBG: Animals treated with $3 \mathrm{~g} \mathrm{~kg}^{-}$ glucose $+30 \mathrm{mg} \mathrm{kg}^{-1}$ MIBG were measured I h postinjections. Mean $\mathrm{pH}_{\mathrm{e}}=6.89 \pm 0.030 ; \mathrm{N}=12 ; n=99$. Acute hypoxia: mice were measured during reoxygenation cycles of 160 min of acute hypoxia treatment. Mean $\mathrm{pH}_{\mathrm{e}}=7.23+0.045, \quad \mathrm{~N}=8 ; \quad n=5 \mathrm{I}$. Acute hypoxia + glucose + MIBG animals were injected with one dose of glucose + MIBG prior to acute hypoxia and were measured as described for acute hypoxia alone. Mean $\mathrm{pH}_{\mathrm{e}}=6.97 \pm 0.03 \mathrm{I} ; \mathrm{N}=5 ; n=32$. (B) Bl6 Fl: animals were measured as described for the KHT-C tumours, unless specified otherwise. Control: all pretreatment measurements were made on the day of the first treatment Mean $\mathrm{pH}_{\mathrm{e}}=7.14+0.022 ; N=19 ; n=152$. Glucose + MIBG: measurements were carried out following I -3 rounds of injections on days 7-9. Mean $\mathrm{pH}_{\mathrm{e}}=6.89 \pm 0.064 ; \quad N=6 ; n=48$. Acute hypoxia: mean $\mathrm{pH}_{\mathrm{e}}=7.0 \mathrm{I} \pm 0.063 ; \bar{N}=4 ; n=33$. Acute hypoxia + glucose + MIBG: mean $\mathrm{pH}_{\mathrm{e}}=6.79 \pm 0.042 ; N=4 ; n=36$. (mean \pm I s.e.m.; $N=$ the number of animals used; $n=$ pooled number of $\mathrm{pH}$ readings obtained).

Figure 2, by making all pretreatment measurements prior to any injections, on day 7. In B16F1 tumours, glucose + MIBG injections resulted in reductions ranging from 0.10 to $0.38 \mathrm{pH}$ units. Thus, although the mean $\mathrm{pH}_{\mathrm{e}}$ in every tumour decreased after each daily treatment, heterogeneity in the responses of individual mice was evident. 
A

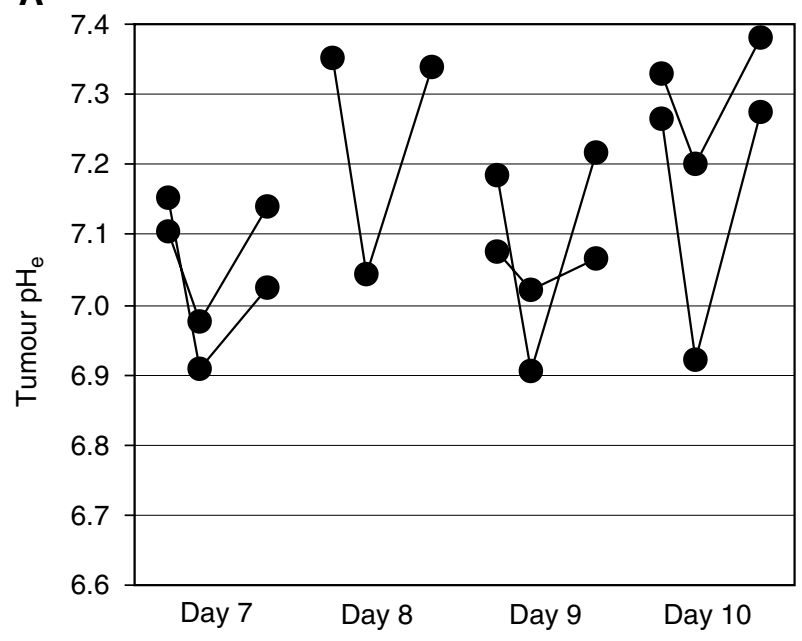

B

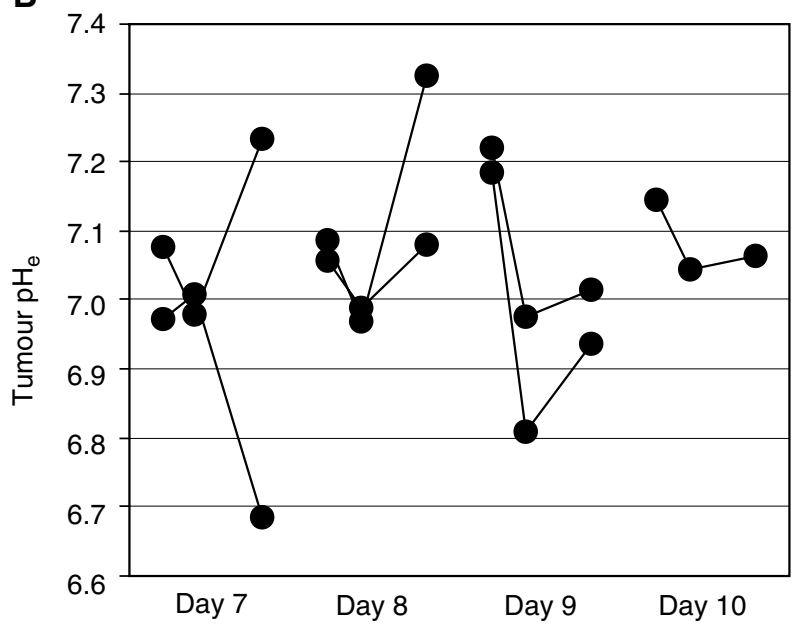

Figure 2 Kinetics of $\mathrm{pH}_{\mathrm{e}}$ reduction following tumour-acidification treatments on four consecutive days in KHT-C and BI6 FI tumours. The distribution of $\mathrm{pH}_{\mathrm{e}}$ was measured daily in total of seven different tumourbearing animals. One animal on day 8 in panel A was omitted due to a missed time point and another animal on day 10 in panel $B$ died. The three connected circles for each animal represent pre-, I h post- and $3 \mathrm{~h}$ postinjection time points. Maximal reduction in mean $\mathrm{pH}_{\mathrm{e}}$ of both tumour models was generally observed at the first time point, I h post-treatment and $\mathrm{pH}_{\mathrm{e}}$ returned near the initial value by $3 \mathrm{~h}$ post-treatment. (A) KHT-C $(N=7)$ : pretreatment measurements were made on each day of the treatment during days $7-10$. Injections consisted of $3 \mathrm{~g} \mathrm{~kg}^{-1}$ glucose $+30 \mathrm{mg} \mathrm{kg}^{-1}$ MIBG on days 7 and 9 and of $3 \mathrm{~g} \mathrm{~kg}^{-1}$ glucose on days 8 and 10. (B) BI6FI $(N=7)$ : all pretreatment measurements were obtained on day 7. The animals were treated with $3 \mathrm{~g} \mathrm{~kg}^{-}$ glucose $+30 \mathrm{mg} \mathrm{kg}^{-1}$ MIBG on days $7-9$ and with $3 \mathrm{~g} \mathrm{~kg}^{-1}$ glucose alone on day 10.

\section{Effects of tumour acidification on $\mathrm{pO}_{2}$}

MIBG is a known inhibitor of mitochondrial respiration (Smets et al, 1988; Biaglow et al, 1998; Loesberg et al, 1990) and a hyperglycaemia-induced shift to glycolysis has been shown to alter cellular oxygen consumption (Nadal-Desbarats et al, 2002). Therefore, we examined whether the glucose + MIBG treatment could result in an increase in tumour $\mathrm{pO}_{2}$ as reported by others (Burd et al, 2001, 2003). The $\mathrm{pO}_{2}$ levels were measured in six KHT$\mathrm{C}$ and two B16F1 tumours with two probes/tumour in all but one case. Recording of data was initiated within $30 \mathrm{~min}$ of glucose + MIBG injections in four KHT-C tumours (Figure 3A) or prior to injections in two KHT-C (Figure 3B) and two B16F1 tumours

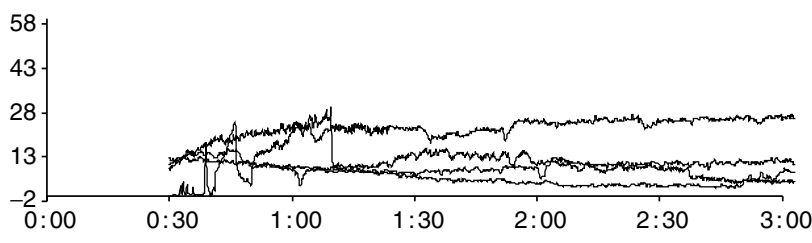

B

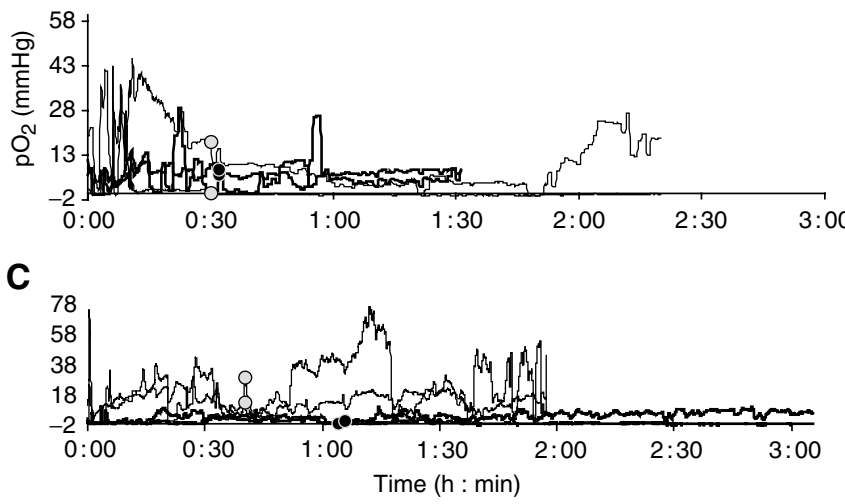

Figure 3 Oxygen tension measurements in $\mathrm{KHT}-\mathrm{C}$ and $\mathrm{B} \mid 6 \mathrm{FI}$ tumours treated with $30 \mathrm{mg} \mathrm{kg}^{-1} \mathrm{MIBG}+3 \mathrm{~g} \mathrm{~kg}^{-1}$ glucose. Most tumours (seven out of eight) were concurrently monitored with two OxyLite probes. No consistent changes in $\mathrm{pO}_{2}$ levels in response to the injections were observed. (A) KHT-C tumours $(N=4)$; measurements were started within 30 min of injections and continued up to $3 \mathrm{~h}$ after treatment. (B) KHT-C tumours $(N=2)$; measurements were started prior to injections, marked by $\mathbf{O}$ and $\mathrm{O}$, and continued for $\mathrm{I}-2 \mathrm{~h}$ after treatment. (C) BI6FI tumours $(N=2)$; measurements were started prior to injections, marked by 0 and $\mathrm{O}$, and continued up to $2 \mathrm{~h}$ after treatment.

(Figure 3C). As reported recently by Brurberg et al (2003), it can take up to $15 \mathrm{~min}$ for measurements with an OxyLite probe to stabilize, hence the early measurements shown in this figure should be viewed with caution. No consistent changes in tumour $\mathrm{pO}_{2}$ levels in response to tumour acidification were observed.

\section{Effects of tumour acidification and acute hypoxia on metastases}

Results of microscopic lung metastasis data from four repeat experiments are shown individually in Table 1 and the combined data is shown in Figure 4. Tumour acidification with glucose + MIBG did not significantly increase the spontaneous metastatic potential of either cell line (KHT-C pooled median: control $=17, \quad$ treatment $=20 ; \quad B 16 \mathrm{~F} 1$ median: $\quad$ control $=1$, treatment $=2$ ). Although the degree of KHT-C tumour acidification achieved with daily glucose injections was less than that achieved glucose + MIBG, we also examined the effects of daily $3 \mathrm{~g} \mathrm{~kg}^{-1}$ glucose injections on metastatic efficiency (mean resultant $\mathrm{pH}_{\mathrm{e}}=7.06 \pm 0.017 ; N=5 ; n=34$ ). The number of micrometastases in this group did not differ from the groups treated with PBS or glucose + MIBG (KHT-C pooled median: control $=17$, treatment $=20$ ). Treatment of the KHT-C tumours with acute hypoxia alone led to a nonsignificant increase in microscopic metastases in three of four experimental repeats (Table 1). None of the treatments had an effect on the metastatic potential of the B16F1 tumours.

\section{DISCUSSION}

Current evidence suggests that the tumour microenvironmental characteristic, acidic $\mathrm{pH}_{\mathrm{e}}$, can be exploited and enhanced to 
Table I Median number of microscopic lung metastases in individual experimental repeats

\begin{tabular}{|c|c|c|c|c|}
\hline & \multicolumn{2}{|c|}{ Air } & \multicolumn{2}{|c|}{ Hypoxia } \\
\hline & PBS & Glu+MIBG & PBS & Glu+MIBG \\
\hline Repeat I & $5(6)$ & $24(6)$ & $17(5)$ & $14(6)$ \\
\hline Repeat 2 & $6(5)$ & $3(5)$ & $13(6)$ & $35(6)$ \\
\hline Repeat 3 & $27(10)$ & $20(10)$ & $35(9)$ & $14(9)$ \\
\hline Repeat 4 & $26(12)$ & $29(12)$ & $18(8)$ & $35(8)$ \\
\hline Median (pasted) & 17 & 20 & 18 & 24 \\
\hline First/third quartiles & $8 / 43$ & $17 / 50$ & $6 / 38$ & | |/48 \\
\hline
\end{tabular}

Hypoxia gassing alone showed an increased number of lung metastases in three of four experiments, although no individual repeat showed statistical significance. Tumour acidification injections with glucose+MIBG resulted in a nonsignificant increase in the number of metastases in two of four experimental repeats both under air control and hypoxic gassing conditions. Number of experimental animals per group is indicated in parenthesis.

improve the efficacy of hyperthermia, certain forms of chemotherapy and photodynamic therapy (Wike-Hooley et al, 1984; Tannock and Rotin, 1989; Jahde et al, 1992; Kuin et al, 1994, 1999; Kozin et al, 2001; Ohtsubo et al, 2001; Piot et al, 2001). However, acidic $\mathrm{pH}$ and lactate have also been associated with enhanced metastatic tumour progression both in experimental models (Schlappack et al, 1991; Jang and Hill, 1997) and clinically (Parkins et al, 1997; Walenta et al, 2000; Brizel et al, 2001). We wanted to determine whether the glucose + MIBG-based tumour-acidifying treatment, used to improve efficacy of cancer therapies, would affect the spontaneous metastatic potential of two murine tumour cell lines, KHT-C and $\mathrm{B} 16 \mathrm{~F} 1$, previously shown to increase their experimental metastatic potential following acidic culture conditions (Schlappack et al, 1991; Jang and Hill, 1997).

Significant acidification of the two tumour types following glucose + MIBG injections was achieved. The mean reduction was $0.24 \mathrm{pH}$ units for KHT-C and $0.25 \mathrm{pH}$ units for B16F1 tumours. Although these reductions are smaller and subsequently return back to original levels faster than has been reported previously following glucose + MIBG treatment in mouse models (Jahde et al, 1992; Kuin et al, 1994), they are very similar to those achieved with glucose treatment alone in cancer patients without local anaesthesia where the mean reduction ranged from 0.16 to $0.19 \mathrm{pH}$ units (Leeper et al, 1998). The difference between studies conducted in mice is likely a combination of the use of different mouse and tumour cell lines, different dose and route of glucose administration and a lower dose of MIBG, which was limited by toxicity. In the B16F1 tumours, which were grown in female mice, this may also be due partly to the sex of the animals since Kuin et al (1994) have previously reported that the degree of RIF-1 tumour acidification was less in female mice than in identically treated male mice.

Despite previously demonstrated cyclical reduction in tumour $\mathrm{pO}_{2}$ during acute hypoxia and evidence for enhanced glycolysis rates following hypoxic culture conditions (Skoyum et al, 1997; Cairns et al, 2001), acute hypoxia resulted in a small reduction in $\mathrm{pH}_{\mathrm{e}}$ only in the $\mathrm{B} 16 \mathrm{~F} 1$ model. The mean change from the untreated control values was $+0.10 \mathrm{pH}$ units for the KHT-C (range: from -0.15 to $+0.41 \mathrm{pH}$ units) and $-0.13 \mathrm{pH}$ units for the $\mathrm{B} 16 \mathrm{~F} 1$ tumours (range: from -0.26 to $+0.14 \mathrm{pH}$ units; Figure 1). The dissimilarity of these two different tumour cell lines in their responses to acute hypoxia may represent an extension of previous reports outlined in the thorough review by Wike-Hooley et al (1984) where the mean $\mathrm{pH}$ values of untreated mouse tumours were reported to vary from a mean of 6.74 (range 6.65-6.93) in a
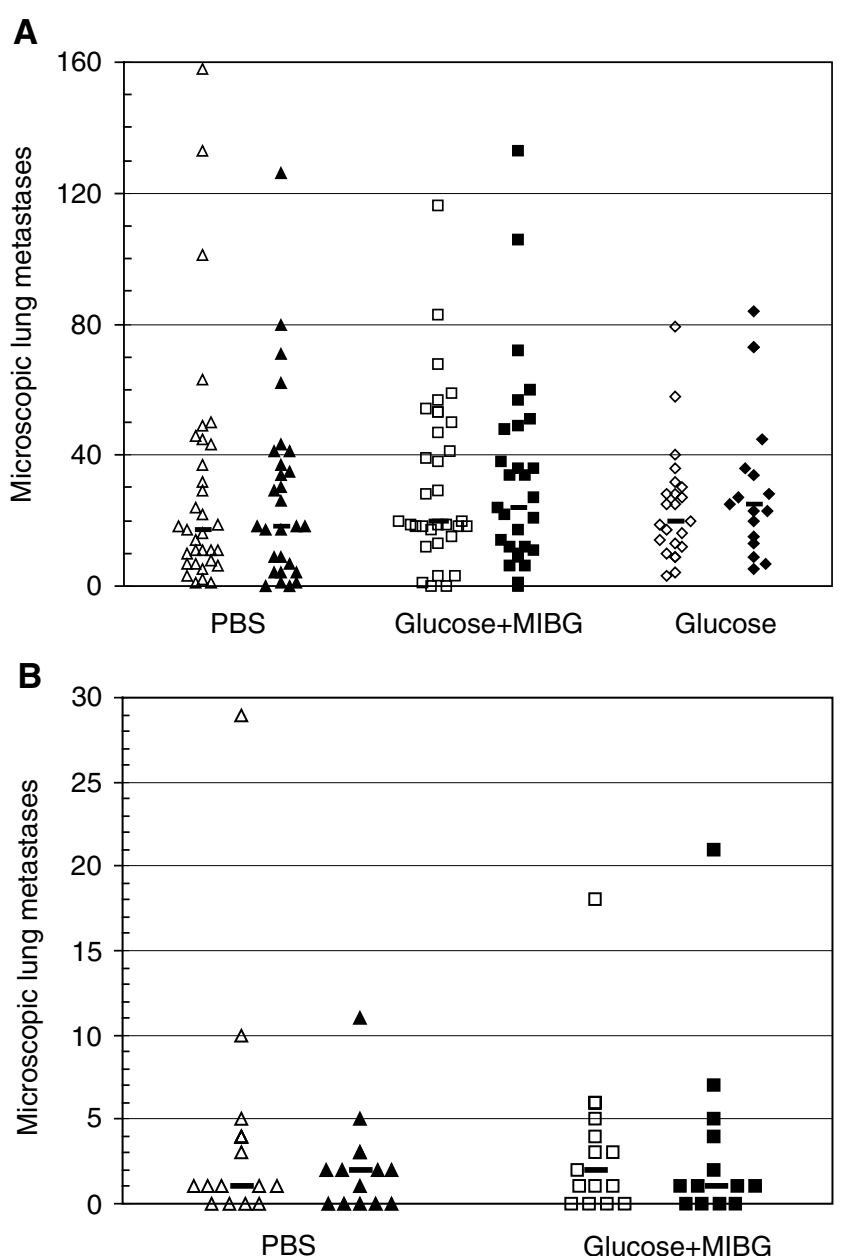

Figure 4 Microscopic lung metastases detected in KHT-C or BI6FI tumour-bearing animals treated with glucose + MIBG $(\square)$, glucose $(\diamond)$ or control injections (PBS, $\triangle$ ) in combination with acute hypoxia or control air gassing conditions, indicated by solid and open symbols, respectively. (A) KHT-C: pooled medians from $2-4$ repeat experiments $(R)$ : Air, PBS $=17$ $(4 \mathrm{R}, N=33) ;$ Air, glucose $+\mathrm{MIBG}=20(4 \mathrm{R}, N=33) ;$ Air, glucose $=20$ $(2 \mathrm{R}, \quad \mathrm{N}=23) ; \quad$ Hypoxia, $\mathrm{PBS}=18 \quad(4 \mathrm{R}, \quad \mathrm{N}=28) ; \quad$ Hypoxia glucose $+M I B G=24(4 R, N=29) ;$ Hypoxia, glucose $=25(2 R, N=17)$. (B) B $6 \mathrm{Fl}$ : medians from one set of experiments: Air, $\mathrm{PBS}=\mathrm{I}(\mathrm{N}=15)$; Air, glucose $+M I B G=2(N=15)$, Hypoxia, $P B S=2(N=14)$; Hypoxia glucose $+\mathrm{MIBG}=1(N=\mid 3)$

hepatoma to a mean of 7.1 (range 6.8-7.4) in a mammary adenocarcinoma.

It was also anticipated that hypoxia-induced oxygen deficiency together with the mitochondrial respiration inhibitor, MIBG, might further shift energy production from aerobic to anaerobic glycolysis with subsequent increase in acid production and further decrease in tumour $\mathrm{pH}_{\mathrm{e}}$. Despite the variability in individual mouse responses to acute hypoxia treatment alone, this appears to hold true for the $\mathrm{B} 16 \mathrm{~F} 1$ tumours as the reduction of $0.35 \mathrm{U}$ in mean tumour $\mathrm{pH}_{\mathrm{e}}$ following the combination treatment is close to the added mean values of 0.13 and $0.25 \mathrm{pH}$ units from acute hypoxia and glucose + MIBG treatments, respectively. The degree of acidification observed with the combination treatment in the KHT-C model (mean change in $\mathrm{pH}_{\mathrm{e}}: 0.16 \mathrm{U}$ ) was less than that seen with glucose + MIBG alone (mean change in $\mathrm{pH}_{\mathrm{e}}: 0.24 \mathrm{U}$ ), which is again consistent with the increase in $\mathrm{pH}_{\mathrm{e}}$ induced by acute hypoxia $\left(0.10 \mathrm{pH}\right.$ units). However, the reason for the increase in $\mathrm{pH}_{\mathrm{e}}$ due to 
exposure to acute hypoxia remains unclear. Tumour cell metabolism has been found to be limited primarily by substrate availability, such as glucose for anaerobic glycolysis, rather than the metabolic demands by tumour cells (Kallinowski et al, 1988; Helmlinger et al, 2002). Therefore, it seems possible that the combination treatment of the KHT-C model caused such a severe depletion of energy stores that little additional acidification from the pre-existing levels was attainable. This alternative is supported by studies by Rotin et al (1986) in which culturing cells under acidic and hypoxic conditions led to a decrease in cellular ATP levels and in the rates of glucose consumption and lactate production. These data are also consistent with the observation where the combination treatment slightly inhibited ( $<1$ day) the development of KHT-C tumours although it had no effect on the growth rate of B16F1 tumours (data not shown).

Previous studies have reported that MIBG can reduce oxygen consumption by tumour cells (Smets et al, 1988; Loesberg et al, 1990; Biaglow et al, 1998;), therefore we examined whether our tumour-acidifying protocol had secondary effects on tumour oxygenation. The KHT-C fibrosarcoma used in this study has previously been shown to be hypoxic with $\mathrm{HP}_{5}$ values (tumour $\mathrm{pO}_{2}$ values $<5 \mathrm{mmHg}$ ) ranging from $25-100 \%$ in individual tumours (median 68\%); similar values have been reported in clinical soft tissue sarcomas with $\mathrm{HP}_{5}$ values ranging from 0-76\% (Brizel et al, 1994; Nordsmark et al, 1996; De Jaeger et al, 2001). We observed no consistent change in tumour $\mathrm{pO}_{2}$ levels following glucose + MIBG injections in either tumour model (Figure 3). If the increase in $\mathrm{pO}_{2}$ levels were immediate, it is possible that the increase would have been missed in our initial study (panel A), as it took approximately $30 \mathrm{~min}$ to start $\mathrm{pO}_{2}$ recording after the injections. However, a group of $\mathrm{pO}_{2}$ measurements (panels $\mathrm{B}$ and C) were made in a set-up that allowed glucose + MIBG injections to be administered without removing the OxyLite probes and again no consistent changes in $\mathrm{pO}_{2}$ levels were observed. A possible explanation for the lack of a detectable change is offered by Kallinowski et al (1989), who postulated that a decrease in oxygen consumption by tumour cells may be concealed by an up to 70 -fold elevation in oxygen consumption by immune cells. Approximately $40 \%$ of cells from dissociated KHT-C tumours have been reported to be immune cells, primarily macrophages (Siemann et al, 1981). Alternatively, this observation may be due to the absence of anaesthetics in the current study, use of which has been reported to influence tissue $\mathrm{pH}_{\mathrm{e}}$ and $\mathrm{pO}_{2}$ (Buelke-Sam et al, 1978; Kerger et al, 1997). These data suggest that the glucose + MIBG-mediated increase in tumour oxygenation and subsequent increase in radiosensitivity reported by Burd et al $(2001,2003)$ may be applicable only to certain tumours.

The absence of a change in the spontaneous metastatic potential in response to in vivo tumour acidification (Figure 4) was unexpected and may be due to inherent differences between the in vitro and in vivo systems. With the KHT-C tumours, the degree of acidification achieved with glucose + MIBG was significant, but was applied only during the second half of total tumour development time for a total of approximately 4 days. While this is consistent with any likely clinical application of such a treatment, it is a considerably shorter time and reduced treatment frequency than that used with animals treated with acute hypoxia. MIBG also had significant growth inhibitory effects on the KHT-C tumours if the injections were started before a palpable tumour was present. Although cell lines are generally highly capable of maintaining alkaline intracellular $\mathrm{pH}\left(\mathrm{pH}_{\mathrm{i}}\right)$ even when the $\mathrm{pH}_{\mathrm{e}}$ is as low as 6.2 (Lee and Tannock, 1998; Kozin et al, 2001), there is evidence that suggests that MIBG acidifies tumour cell $\mathrm{pH}_{\mathrm{i}}$ via an unknown mechanism (Biaglow et al, 1998; Kuin et al, 1999; Zhou et al, 2000). It is therefore possible that MIBG-induced cytotoxic effects may have counteracted the potential metastasis promoting effects of tumour acidification. In an attempt to examine less toxic methods to achieve tumour acidification and to increase the number of days when the treatment was implementable, we tested carbogen $\left(95 \% \mathrm{O}_{2} / 5 \% \mathrm{CO}_{2}\right)$ breathing, which has been reported to result in significant tumour-specific acidification without growth inhibition (Stubbs et al, 1998). However, we saw no change in mean $\mathrm{pH}_{\mathrm{e}}$ of the KHT-C tumours following $2 \mathrm{~h}$ of carbogen breathing (data not shown). To rule out the potential of MIBGinduced increases in tumour oxygenation and subsequent possibility of inhibition of metastasis formation, the tumouracidifying treatment was also combined with acute hypoxia. The median number of lung metastases in this combination treatment group did not differ from the medians of the groups receiving either treatment alone. We believe that this addition of hypoxia to the tumour-acidifying regime should have been able to compensate any possible increases in tumour oxygenation and thus prevent masking of a positive effect of acidification on metastasis formation. We also examined the power of our data set to detect a difference. Based on this analysis, the data for MIBG + glucose has $80 \%$ power to detect a difference greater than 2.7 -fold in metastasis formation. We conclude that if the $\mathrm{pH}_{e}$ changes induced by the treatment do cause an effect, it is unlikely to be larger than a 2.7fold difference.

Owing to higher tolerance to MIBG, the B16F1 tumour model received tumour-acidifying injections longer and more frequently than the KHT-C model. The maximal degree of acidification was also higher in the $\mathrm{B} 16 \mathrm{~F} 1$ model $(0.35 \mathrm{pH}$ units $v s 0.24 \mathrm{pH}$ units for KHT-C). Despite this, no increase in metastases was observed contrary to our previous in vitro studies (Schlappack et al, 1991; Jang and Hill, 1997). The maximal mean reduction achieved in vivo remained significantly lower than the reduction of $0.7 \mathrm{pH}$ units achieved in vitro (control $\mathrm{pH} 7.2$, treatment $\mathrm{pH} 6.5$ ). The acidic conditions were also maintained much longer in vitro $(48 \mathrm{~h}$, followed by a $24-48 \mathrm{~h}$ recovery period) than in vivo $(<3 \mathrm{~h})$. Thus, the acidic exposure in vitro was much more severe than could be achieved in vivo, which may explain the differences in the results obtained. This outcome may also be partially due to the low spontaneous metastatic efficiency of the $\mathrm{B} 16 \mathrm{~F} 1$ cell line. It is well known that growth site of the primary tumour can have a significant impact on the (metastatic) outcome of any given experiments and the predominant view supports an orthotopic rather than nonorthotopic site for maximal spontaneous metastatic effect (Manzotti et al, 1993; Blouw et al, 2003). It is possible that in our case, intradermally injected tumours might have given more metastases, however, such tumours tend to ulcerate at small sizes and we felt that they would be unsuitable for a study involving multiple needle insertions (personal observation, $\mathrm{R}$ Kuba).

In light of our previous data, which showed a significant increase in experimental metastatic potential by KHT-C and $\mathrm{B} 16 \mathrm{~F} 1$ cells following acidic culture conditions, the absence of an increase in spontaneous metastases underscores the complexity associated with the effect of the tumour microenvironment on malignant disease progression. Together with studies using noninvasive, in vivo $\mathrm{pH}$ quantifying imaging techniques, such as those described Gillies et al (2002), the current study, attaining a degree of tumour-acidification matching that achieved in the clinics, should provide valuable information about the potential risk-benefit ratio of tumour-acidification treatment in humans.

\section{ACKNOWLEDGEMENTS}

We thank Dr Mark Dewhirst for the gift of MIBG, Robert Kuba for expert technical assistance and Drs Hedley, Tannock and Minkin for helpful discussions. This work was supported by a grant from the National Cancer Institute of Canada with funds raised by the Terry Fox Run. 


\section{REFERENCES}

Bausell RB, Li Y-F (Eds) (2002) 'Power Analysis for Experimental Research. A Practical Guide of the Biological, Medical and Social Sciences', pp. 4, 56 Cambridge, UK: Cambridge University Press

Biaglow JE, Manevich Y, Leeper D, Chance B, Dewhirst MW, Jenkins WT, Tuttle SW, Wroblewski K, Glickson JD, Stevens C, Evans SM (1998) MIBG inhibits respiration: potential for radio- and hyperthermic sensitization. Int J Radiat Oncol Biol Phys 42: 871-876

Blouw B, Song H, Tihan T, Bosze J, Ferrara N, Gerber HP, Johnson RS, Bergers G (2003) The hypoxic response of tumors is dependent on their microenvironment. Cancer Cell 4: 133-146

Bristow RG, Hardy PA, Hill RP (1990) Comparison between in vitro radiosensitivity and in vivo radioresponse of murine tumor cell lines. I: parameters of in vitro radiosensitivity and endogenous cellular glutathione levels. Int J Radiat Oncol Biol Phys 18: 133-145

Brizel DM, Rosner GL, Harrelson J, Prosnitz LR, Dewhirst MW (1994) Pretreatment oxygenation profiles of human soft tissue sarcomas. Int $J$ Radiat Oncol Biol Phys 30: 635-642

Brizel DM, Schroeder T, Scher RL, Walenta S, Clough RW, Dewhirst MW, Mueller-Klieser W (2001) Elevated tumor lactate concentrations predict for an increased risk of metastases in head-and-neck cancer. Int J Radiat Oncol Biol Phys 51: 349-353

Brurberg KG, Graff BA, Rofstad EK (2003) Temporal heterogeneity in oxygen tension in human melanoma xenografts. Br J Cancer 89: 350 - 356

Buelke-Sam J, Holson JF, Bazare JJ, Young JF (1978) Comparative stability of physiological parameters during sustained anesthesia in rats. $L a b$ Anim Sci 28: $157-162$

Burd R, Lavorgna SN, Daskalakis C, Wachsberger PR, Wahl ML, Biaglow JE, Stevens CW, Leeper DB (2003) Tumor oxygenation and acidification are increased in melanoma xenografts after exposure to hyperglycemia and meta-iodo-benzylguanidine. Radiat Res 159: 328-335

Burd R, Wachsberger PR, Biaglow JE, Wahl ML, Lee I, Leeper DB (2001) Absence of Crabtree effect in human melanoma cells adapted to growth at low pH: reversal by respiratory inhibitors. Cancer Res 61: 5630-5635

Cairns RA, Kalliomaki T, Hill RP (2001) Acute (cyclic) hypoxia enhances spontaneous metastasis of KHT murine tumors. Cancer Res 61: $8903-$ 8908

De Jaeger K, Kavanagh MC, Hill RP (2001) Relationship of hypoxia to metastatic ability in rodent tumors. Br J Cancer 84: 1280-1285

Fukumura D, Xu L, Chen Y, Gohongi T, Seed B, Jain RK (2001) Hypoxia and acidosis independently up-regulate vascular endothelial growth factor transcription in brain tumors in vivo. Cancer Res 61: 6020-6024

Gillies RJ, Raghunand N, Karczmar GS, Bhujwalla ZM (2002) MRI of the tumor microenvironment. J Magn Reson Imaging 16: $430-450$

Griffiths JR, McIntyre DJ, Howe FA, Stubbs M (2001) Why are cancers acidic? A carrier-mediated diffusion model for $\mathrm{H}+$ transport in the interstitial fluid. Novart Found Symp 240: 46-62

Helmlinger G, Sckell A, Dellian M, Forbes NS, Jain RK (2002) Acid production in glycolysis-impaired tumors provides new insights into tumor metabolism. Clin Cancer Res 8: 1284-1291

Helmlinger G, Yuan F, Dellian M, Jain RK (1997) Interstitial pH and $\mathrm{pO}_{2}$ gradients in solid tumors in vivo: high-resolution measurements reveal a lack of correlation. Nat Med 3: 177-182

Hill RP, De Jaeger K, Jang A, Cairns R (2001) pH, hypoxia and metastasis. Novartis Found Symp 240: 154-165

Jahde E, Volk T, Atema A, Smets LA, Glusenkamp KH, Rajewsky MF (1992) $\mathrm{pH}$ in human tumor xenografts and transplanted rat tumors: effect of insulin, inorganic phosphate, and m-iodobenzylguanidine. Cancer Res 52: $6209-6215$

Jang A, Hill RP (1997) An examination of the effects of hypoxia, acidosis, and glucose starvation on the expression of metastasis-associated genes in murine tumor cells. Clin Exp Metast 15: 469-483

Kallinowski F, Tyler G, Mueller-Klieser W, Vaupel P (1989) Growth-related changes of oxygen consumption rates of tumor cells grown in vitro and in vivo. J Cell Physiol 138: $183-191$

Kallinowski F, Vaupel P, Runkel S, Berg G, Fortmeyer HP, Baessler KH, Wagner K, Mueller-Klieser W, Walenta S (1988) Glucose uptake, lactate release, ketone body turnover, metabolic micromilieu, and $\mathrm{pH}$ distributions in human breast cancer xenografts in nude rats. Cancer Res 48: $7264-7272$

Kato Y, Nakayama Y, Umeda M, Miyazaki K (1992) Induction of 103-kDa gelatinase/type IV collagenase by acidic culture conditions in mouse metastatic melanoma cell lines. J Biol Chem 267: 11424-11430
Kerger H, Saltzman DJ, Gonzales A, Tsai AG, van Ackern K, Winslow RM, Intaglietta M (1997) Microvascular oxygen delivery and interstitial oxygenation during sodium pentobarbital anesthesia. Anesthesiology 86: $372-386$

Kozin SV, Shkarin P, Gerweck LE (2001) The cell transmembrane pH gradient in tumors enhances cytotoxicity of specific weak acid chemotherapeutics. Cancer Res 61: $4740-4743$

Kuin A, Aalders M, Lamfers M, van Zuidam DJ, Essers M, Beijnen JH, Smets LA (1999) Potentiation of anti-cancer drug activity at low intratumoral $\mathrm{pH}$ induced by the mitochondrial inhibitor m-iodobenzylguanidine (MIBG) and its analogue benzylguanidine (BG). Br J Cancer 79: $793-801$

Kuin A, Smets L, Volk T, Paans A, Adams G, Atema A, Jahde E, Maas A Rajewsky MF, Visser G, Wood B (1994) Reduction of intratumoral pH by the mitochondrial inhibitor m-iodobenzylguanidine and moderate hyperglycemia. Cancer Res 54: 3785-3792

Lee AH, Tannock IF (1998) Heterogeneity of intracellular $\mathrm{pH}$ and of mechanisms that regulate intracellular $\mathrm{pH}$ in populations of cultured cells. Cancer Res 58: $1901-1908$

Leeper DB, Engin K, Wang JH, Cater JR, Li DJ (1998) Effect of i.v. glucose versus combined i.v. plus oral glucose on human tumour extracellular $\mathrm{pH}$ for potential sensitization to thermoradiotherapy. Int J Hyperther 14: $257-269$

Loesberg C, Van Rooij H, Nooijen WJ, Meijer AJ, Smets LA (1990) Impaired mitochondrial respiration and stimulated glycolysis by m-iodobenzylguanidine (MIBG). Int J Cancer 46: 276-281

Manzotti C, Audisio RA, Pratesi G (1993) Importance of orthotopic implantation for human tumors as model systems: relevance to metastasis and invasion. Clin Exp Metast. 11: 5-14

Martinez-Zaguilan R, Seftor EA, Seftor RE, Chu YW, Gillies RJ, Hendrix MJ (1996) Acidic $\mathrm{pH}$ enhances the invasive behavior of human melanoma cells. Clin Exp Metast 14: 176-186

Nadal-Desbarats L, Poptani H, Oprysko P, Jenkins WT, Busch TM, Nelson DS, Glickson JD, Koch CJ, Evans SM (2002) Effects of hyperglycemia on oxygenation, radiosensitivity and bioenergetic status of subcutaneous RIF-1 tumors. Int J Oncol 21: $103-110$

Newell K, Franchi A, Pouyssegur J, Tannock I (1993) Studies with glycolysis-deficient cells suggest that production of lactic acid is not the only cause of tumor acidity. Proc Natl Acad Sci USA 90: 1127-1131

Nordsmark M, Hoyer M, Keller J, Nielsen OS, Jensen OM, Overgaard J (1996) The relationship between tumor oxygenation and cell proliferation in human soft tissue sarcomas. Int J Radiat Oncol Biol Phys 35: 701 708

Ohtsubo T, Igawa H, Saito T, Matsumoto H, Park HJ, Song CW, Kano E, Saito H (2001) Acidic environment modifies heat- or radiation-induced apoptosis in human maxillary cancer cells. Int J Radiat Oncol Biol Phys 49: $1391-1398$

Parkins CS, Stratford MR, Dennis MF, Stubbs M, Chaplin DJ (1997) The relationship between extracellular lactate and tumour $\mathrm{pH}$ in a murine tumour model of ischaemia-reperfusion. Br J Cancer 75: 319-323

Piot B, Rousset N, Lenz P, Eleouet S, Carre J, Vonarx V, Bourre L, Patrice T (2001) Enhancement of delta aminolevulinic acid-photodynamic therapy in vivo by decreasing tumor $\mathrm{pH}$ with glucose and amiloride. Laryngoscope 111: 2205-2213

Rofstad EK (2000) Microenvironment-induced cancer metastasis. Int J Radiat Biol 76: 589-605

Rotin D, Robinson B, Tannock IF (1986) Influence of hypoxia and an acidic environment on the metabolism and viability of cultured cells: potential implications for cell death in tumors. Cancer Res 46: $2821-2826$

Schlappack OK, Zimmermann A, Hill RP (1991) Glucose starvation and acidosis: effect on experimental metastatic potential, DNA content and MTX resistance of murine tumour cells. Br J Cancer 64: 663-670

Shi Q, Abbruzzese JL, Huang S, Fidler IJ, Xiong Q, Xie K (1999) Constitutive and inducible interleukin 8 expression by hypoxia and acidosis renders human pancreatic cancer cells more tumorigenic and metastatic. Clin Cancer Res 5: $3711-3721$

Shi Q, Le X, Wang B, Abbruzzese JL, Xiong Q, He Y, Xie K (2001) Regulation of vascular endothelial growth factor expression by acidosis in human cancer cells. Oncogene 20: $3751-3756$

Siemann DW, Lord EM, Keng PC, Wheeler KT (1981) Cell subpopulations dispersed from solid tumours and separated by centrifugal elutriation. $\mathrm{Br}$ J Cancer 44: $100-108$ 
Skoyum R, Eide K, Berg K, Rofstad EK (1997) Energy metabolism in human melanoma cells under hypoxic and acidic conditions in vitro. Br J Cancer 76: $421-428$

Smets LA, Bout B, Wisse J (1988) Cytotoxic and antitumor effects of the norepinephrine analogue meta-iodo-benzylguanidine (MIBG). Cancer Chemother Pharmacol 21: 9-13

Stubbs M, McSheehy PM, Griffiths JR, Bashford CL (2000) Causes and consequences of tumour acidity and implications for treatment. Mol Med Today 6: $15-19$

Stubbs M, Robinson SP, Rodrigues LM, Parkins CS, Collingridge DR, Griffiths JR (1998) The effects of host carbogen (95\% oxygen/5\% carbon dioxide) breathing on metabolic characteristics of Morris hepatoma 9618a. Br J Cancer 78: 1449-1456

Tannock IF, Rotin D (1989) Acid pH in tumors and its potential for therapeutic exploitation. Cancer Res 49: 4373-4384

Thistlethwaite AJ, Alexander GA, Moylan III DJ, Leeper DB (1987) Modification of human tumor $\mathrm{pH}$ by elevation of blood glucose. Int J Radiat Oncol Biol Phys 13: 603-610
Walenta S, Wetterling M, Lehrke M, Schwickert G, Sundfor K, Rofstad EK, Mueller-Klieser W (2000) High lactate levels predict likelihood of metastases, tumor recurrence, and restricted patient survival in human cervical cancers. Cancer Res 60: 916-921

Wike-Hooley JL, Haveman J, Reinhold HS (1984) The relevance of tumour $\mathrm{pH}$ to the treatment of malignant disease. Radiother Oncol 2: $343-366$

Workman P, Twentyman P, Balkwill F, Balmain A, Chaplin D, Double J, Embleton J, Newell D, Raymond R, Stables J, Stephens T, Wallace J (1998) United Kingdom Co-ordinating Committee on Cancer Research (UKCCCR) Guidelines for the Welfare of Animals in Experimental Neoplasia (2nd edn.). Br J Cancer 77: 1 - 10

$\mathrm{Xu} \mathrm{L}$, Fidler IJ (2000) Acidic pH-induced elevation in interleukin 8 expression by human ovarian carcinoma cells. Cancer Res 60: 4610 - 4616

Zhou R, Bansal N, Leeper DB, Glickson JD (2000) Intracellular acidification of human melanoma xenografts by the respiratory inhibitor miodobenzylguanidine plus hyperglycemia: a 31P magnetic resonance spectroscopy study. Cancer Res 60: $3532-3536$ 